\title{
Utilizing the Analysis of Social Practices to Raise Critical Language Awareness in EFL Writing Courses
}

\author{
Parviz Maftoon \\ Islamic Azad University Science and Research Branch, Tehran, Iran \\ Email: pmaftoon@gmail.com \\ Soroush Sabbaghan \\ Islamic Azad University Science and Research Branch, Tehran, Iran \\ Email: inproxima@yahoo.com
}

\begin{abstract}
Language can be used as a means to control and influence people. EFL students need to realize that the language they interact with may contain ideological assumptions and propositional meanings. By increasing critical language awareness, students may come to recognize ideological assumptions within the language. Fairclough (2003) suggests that one of the ways to increase critical language awareness is to identify social practices, defined as rules and structures that limit human actions and interaction within a context. The elements of order of discourse- genre, discourse, and style - are the linguistic rules of social practices. The goal of this study was to provide a method for EFL teachers to increase students' critical awareness through writing. The participants consisted of 16 teacher trainees and 10 university students who performed a journalwriting task over 10 sessions. Feedback, based on the elements of order of discourse, was provided after each session, and the participants were asked to consider the feedback for their next journal entry. After 10 sessions, the journals were quantified and regression analysis was used to calculate the slope polarity of the best fitting line. The results indicate that the scores of the majority of the participants increased.
\end{abstract}

Index Terms - critical language awareness, critical discourse analysis, social practices

\section{INTRODUCTION}

Language can be used as a means to control people and to influence what they think and do (see Bolinger, 1990; Bourdieu, 1991; Fairclough, 1995). The choice of words, sentence structure, register, or discourse structure can radically alter people's perceptions toward a method, a belief, or an ideology. For example, a choice of lexis might either justify police brutality as an appropriate method of suppressing a dangerous criminal, or render the police officers as vicious law officials who abuse power. A classic example of manipulation is changing the structure of a sentence by using the passive voice, which is used to conceal facts. For example, if a politician says, "mistakes were made," we might not immediately ask "what mistakes exactly?" or "how many mistakes are you talking about?" or even "who made the mistakes?"

Critical discourse analysis (CDA) is a type of research which attempts to reveal the connections between language use, power, and ideology. CDA recognizes that languages uses can influence and be influenced by language. One of the research objectives of CDA (see Fairclough, 1992b) is analogous to a goal of critical language awareness, which is to raise students' awareness of how language is used so that others cannot easily manipulate them. In other words, students need to be aware that in some cases language is used to satisfy a secondary or hidden agenda. Raising critical language awareness enables students to understand issues regarding power and control as well as the role that language plays in these issues.

According to van Lier(1998; 2004), language awareness develops through social interaction. He asserts that focusing on certain linguistic elements in the environment is required to raise critical language awareness. Fairclough (2004) suggested a framework that explains what aspects of language should be focused on to increase critical language awareness.

Fairclough's (2004) framework was developed by studying human interactions in society via the science of social ontology. Social ontology assumes that what can exist (or is possible) in a society is abstract, also referred to as abstract social structures. What is, or what already exists in a society is concrete, labeled as social events.

Social structures are a set of potentials that include some possibilities and exclude others (Fairclough, 2003). For example, the beliefs and values of a Muslim religious family could be construed as a social structure. Such a family will choose to eat only Halal foods. Although this choice will entitle them to a wide range of food, it also excludes certain foods. Likewise, language is an element of social structure; it allows for a set of possibilities and excludes others. For example, "a book" is a possible phrase in English, "book a" is not. 
Football games, university class lectures, or symposiums are all social events. In other words, they exist in our society. People interact in these social events, and these interactions are either spoken or written. Fairclough (2003) calls these interactions texts. In some social events, a great deal of text is required and in others, very little text is created. For example, a football game produces little text because this social event requires minimal linguistic action (except maybe yelling for the ball). A classroom lecture is also a social event, but the actions in the classroom are usually linguistic in nature; what the lecturer says, what is seen on the video projector, and what students write down are all considered to be texts.

Social events and their texts do not happen randomly. There are factors that shape the events and texts. Fairclough (2003) believes there are two causes that form social events and their texts. The first cause is the social agent, or people who are involved in the social event. Social agents are not free to say or write anything they want because of social, ideological, or personal constraints. The second cause is limitations and sets of intermediate rules that regulate how texts are produced. In other words, these rules are selected from what is possible in social structures. Fairclough (2003) refers to these rules as social practices. Social practices are formed over long periods of time, and there are many types of social practices that govern a social event. The different types of social practices form networks. These networks define ways of acting and interacting via speaking and writing. For example, the way schoolteachers interact with their students in the classroom has changed over the last 50 years. These changes have occurred through shifts in networks of social practices. These shifts include the ban on beating children, using verbal abuse, and the use of a less formal tone in the classroom.

Some of the rules and limitations imposed by social practices are linguistic. The linguistic restrictions of social practices do not only include grammatical rules. There are other organizational entities, which Fairclough (2003, 2004) calls orders of discourse. The elements of orders of discourse allow for a set of linguistic possibilities and exclude others. For example, in a formal interview, the elements of the order of discourse allow a wide variety of topics to be discussed. However, they restrict interaction on private or personal matters. These elements are not nouns, verbs or adjectives; instead, the elements consist of genres, discourses, and styles. Therefore, to increase critical language awareness, students need to be trained to identify genres, discourses, and styles within texts.

Genres are expressed as "ways of acting" (Fairclough, 2004, p. 228) or "language tied to a particular social activity" (Chouliaraki \& Fairclough, 1999, p. 63); they can manifest themselves as interviews or sermons. Accordingly, writing journals about learning, as long as the teacher provides feedback, is an interaction or a text (see Chouliaraki \& Fairclough, 1999, for other examples). In other words, certain aspects of the language should indicate that a written text is a learning journal. For example, a learning journal should have a theme, which indicates what was taught in a particular session. In sum, genres are responsible for putting meaning and content in a context.

The next element of order of discourse is called discourse. Discourses are basically "ways of representing" (Fairclough, 2004, p. 228) or "construction of some aspect of reality from a particular perspective" (Chouliaraki \& Fairclough, 1999, p. 63). Different discourses are in essence different perspectives of the world. People have different perspectives because they exist in different contexts and have different and unique identities.

Discourses are evident in political commentary used by governments. Phrases such as "terrorism," "axis of evil," or "weapons of mass destruction" are intended to promote fear and distrust as well as to keep people apart. Conversely, words could be used to bring people together. It is important to note that social relationships are not only established by discourses; they are just one element that can be used to make or change relationships.

The third and final element of order of discourse is called style. Style is defined as "language used for a particular category of people and closely linked to their Identity" (Chouliaraki \& Fairclough, 1999, p. 63). Who you are is partly defined by how you speak (or write). Styles can be realized through pronunciation, intonation, stress, and rhythm. For example, most medical doctors use specific lexis and phrases, which indicate that the person speaking or writing is a medical doctor. In other words, their choice of lexis has indicated part of their identity. However, in identifying style in written texts, we focus on the choice of vocabulary.

In a learning journal, being able to express a new ability or a change in a belief, for example, could be considered the style of a student. In our study, a participant wrote in one of his journal entries "today I learned how to mind map." This is a classic example of using language to show that a student is learning new material. If we were to guess the identity of the person who wrote this sentence in isolation, we would probably say that this person is a student of some kind.

If students are able to identify the elements of order of discourse, they will be able to critically analyze linguistic actions and interactions. This will increase their ability to look at language critically, which in turn increases critical language awareness. The goal of this research study was to familiarize students with these elements through writing learning journals. It is hypothesized that when students repeatedly observe how elements of order of discourse are applied to their journal entries, they would learn to apply these tools, which would ultimately increase their level of critical language awareness.

\section{METHOD}

Two groups of participants took part in this study. Members of the first group (group A) were all EFL teacher trainees at one of Tehran's larger language institutes. They consisted of 10 females and 6 males. All took the Oxford Placement Test (Allen, 2004) and obtained a score of 150 or higher, which designated them as advanced users of 
English. The second group (group B) consisted of 3 male and 7 female English literature students who sat for the Oxford Placement Test and obtained scores between 135 and 150, which designated them as competent users of English.

Both groups were provided with an explanation of the research and its purposes in a briefing session. Participants in group A were allowed to discontinue participating in the project at any time because they were not given any incentive and participation was on a voluntary basis, but participants in group B were told that the research was part of their class credit and that participation was mandatory.

Both groups were asked to carry out a journal-writing task focusing on the topic of learning for 10 sessions. Guidelines on how to write a journal were adopted from Moon (1999) and given to all participants (see Appendix C). The guidelines explained what was to be written in the journal. These guidelines were provided because it was anticipated that if the participants did not fully understand what was expected of them, they would write very little and, as a result, would have trouble identifying the elements of order of discourse.

In addition to the Oxford Placement Test, a critical discourse feedback form (see Appendix A) and a critical discourse assessment questionnaire (see Appendix B) were also used in the study. The critical discourse feedback form was created to ease the analysis of the learning journals. All three elements were broken into subsections to help students more accurately identify the elements of order of discourse. These subsections were developed based on Chouliaraki and Fairclough's (1999) account of genre, discourse, and style as well as on the findings of other scholars(Fairclough, 2004; Lewis \& Ketter, 2004; Rogers, 2004; Sarroub, 2004; Woodside-Jiron, 2004).

The critical discourse feedback form consisted of three sections. The first section was genre, which had 6 subsections. These subsections were theme, information focus, paragraph formation, cohesion devices, L1 influence, and literary devices. These subsections were selected based on Chouliaraki and Fairclough's (1999) description of genre. The researchers expected that journals written by EFL students should include these subsections.

The first subsection, theme, referred to the topic of study in the students' classes. For example, in this study, two of the themes were compare and contrast paragraphs and classroom management. The theme limits the scope of the journal entry. For instance, when the theme is classroom management, one does not expect to read about how to teach reading. The next subsection was information focus, which referred to the topic area the participants chose to talk about. For example, an information focus in this study for the theme of "classroom management" was the way the instructor taught classroom management, or how the topic of classroom management was interesting or boring. The next subsection was paragraph formation. This subsection indicated the separation of information focus. This type of organization is expected in journal writing, which is why it was included as a subsection of genre.

The next subsection was the total number of cohesive devices, which is important in a journal entry because events should be labeled using appropriate lexical categories such as adverbs and conjunctions (Moon, 1999; Sparks-Langer \& Colto, 1991; Sparks-Langer, Simmons, Pasch, Colton, \& Starko, 1990). For example, presenting events in a chronological order might demonstrate a reflection of the events that took place.

The next subsection, the number of incidents where L1 influence is observed, may not be restricted to journal writing; nevertheless, the category was added to give feedback to the writer on what should not be written or what is not linguistically possible. For example, one participant wrote, "The scores of the midterm exams is coming this week. I have a lot of stress, I know I should be more careless, but I can't." As mentioned before, genres are ways of acting or interacting. A non-native speaker of Persian might not understand why the student should be more careless. If careless was translated into Persian, its meaning would change from "clumsy" in English to "care-free" in Persian. Informing the writers of this mistake probably increased their awareness of these types of errors and might have provoked the formation of a practice of double checking meanings that are lost in translation.

The next subcategory, the number of literary devices, is an important subsection of genre. Literary devices show creative thinking and the depth and detail of reflection. Fairclough (2003) considers the use of literary devices as part of a native speaker's discourse (way of representing). However, the researchers believe that EFL students should be able to interact with each other using literary devices and, in journal writing, the students should be creative and descriptive about events that occurred in the classroom. In other words, using literary devices is expected from a competent and proficient language user, hence for the language user, literary devices fall into the genre section.

Discourse or ways of representing was the next section. This section consisted of three subsections: point of view or perspective, possible interpretation, and challenges or disagreements. The first subsection, point of view, was selected to identify the participants' degree of awareness of other pupils' thoughts and insights in class. For example, for the theme of "learning vocabulary," one participant wrote, "she [one of the students in the class] said that the best way to learn vocabulary is learning the correct pronunciation and that the correct pronunciation 'stuck' in her mind." This participant later mentions, "I don't think pronunciation is the most important factor in vocabulary learning." Based on what the participant has written, it seems that she has the ability to observe different points of view and evaluate them. In other words, this participant was able to distinguish a point of view that was different from her own, evaluate it, and reflect upon it by mentioning it in her journal.

The next subsection, possible interpretations, refers to the general mood or message the participant was trying to convey. For example, one participant asked an assessor five times about how to improve his writing. In previous feedback forms, he felt others were improving while he was not. This interaction between the participant and the 
assessor is a clear indication of anxiety. If others read this entry, they would probably conclude that because the student repetitively inquired about his writing ability, he was anxious and worried.

The last subcategory was challenges or disagreements. One example of a challenge/disagreement occurred when a participant wrote, "I dislike the speed of his [the instructor's] teaching; it is fast for me." Another wrote, "I think that during his [a fellow trainee's] lesson there was a high level of Teacher Talk Time. He should have kept his talking time to a minimum." These two examples were categorized under challenges or disagreements. When people challenge or disagree with others, they are actually establishing a relationship. The words and phrases used to challenge or even disagree might indicate dominance of one person or idea over the other.

The last section, style, is a particular way of speaking or writing that reveals information on identity. In other words, the language used by participants in this study should indicate that the writers are studying English. Style consists of 9 subcategories: pronoun variation, passive formation, tense variation, affinity, use of modal verbs, affective transitivity, cognitive transitivity, ability transitivity, and register.

The first subsection, pronoun variation, referred to the use of the first, second, and third person. English students usually communicate with other students and reflect upon each other's opinions. This category is important because changes in point of view demonstrate how a participant views himself or herself in relation to others. For example, the use of the first person singular could be an indication of solitude, whereas the use of first person plural might indicate unification, or siding with a particular group. Participants who show more points of view demonstrate that they have more contact with other students and that they have considered and reflected upon those interactions.

The next subsection examines the number of passive verbs used. The number of passive verbs was counted in this section because the passive voice is usually used in the written text of English students to show impersonality. It might even be construed as a sign of humbleness. Other times, the passive tense is used to hide something. For example, one participant wrote "there was much disagreement about 'on the spot' error correction." It seems that this student does not want to mention who disagreed with this form of error correction perhaps because she does not want the assessor of the journals to know.

The next subsection was tense variation, which referred to the extent to which state of time (past, present, and future) and their aspects (simple, continuous, and perfect) were used. Varieties of tenses indicate depth of reflection. In other words, a variety of tenses was an indication that the participants had reflected on events from the past and pondered upon them. Journal descriptions of different events and actions at different points in time indicated that the participant was attentive in the classroom. The variation in verb tense is important because the students were expected to be vigilant during class, and variation in tense within the journal descriptions might reflect this vigilance.

The next subsection, affinity, referred to the ability to say something in a manner that did not hurt one's feelings. This is a very important quality for language students to have. For instance, a participant wrote, "I hope all this material we have to learn does not go to waste :)." The use of the smiley face when considering that the participant was expressing distrust was taken as a sign of affinity.

The next subsection, the use of modal verbs, referred to the extent to which modal verbs were used in the journal. Modal verbs are a good indication of how the participants see themselves in relation to others and are a good indication of how students express emotions. For example, using modal verbs that denote certainty might indicate confidence of the participant, whereas model verbs that express probability or possibility might be an indication of tact.

The subsections of affective transitivity, cognitive transitivity, and ability transitivity need to be discussed separately because they are more elaborate. Chouliaraki and Fairclough (1999) have stated that transitivity can be used for analyzing style. Fairclough (1992) has suggested that transitivity includes the analysis of process types. He has also suggested that process types in a text can be categorized into "actions, events, relational and mental" (p. 180). When Fairclough (1992, p. 180), discussed actions, he distinguished between direct actions and indirect actions. A direct action refers to an agent acting upon a goal. For example, in "the teenager kicked the dog," the process is a direct action because there is an agent, an action, and a goal. However, in "the teenager was kicking" the process is indirect because there is an agent and an action, but there is no goal involved. For the purpose of text analysis, the distinction between direct and non-direct processes was not made because the researchers felt it would confuse participants. Both processes were classified as one category called ability transitivity.

In the context of learning journals, ability transitivity referred to the expression of new skills that the participants had developed. Being able to express new abilities is part of being a student. Mental processes were divided into two categories of affective transitivity and cognitive transitivity. Affective transitivity, in the context of journal writing, refers to the ability to express wants and desires; cognitive transitivity refers to the ability to express beliefs and attitudes. Being able to express new beliefs or rejecting them is part of the text a student produces (Wenden, 1986).

Students also should be able to express what they want to learn, or what learning they would pursue in the future (Sinclair, McGrath, \& Lamb, 2000). Event processes can focus on the mastery of the materials learned because these processes "involve an event and a goal" (Fairclough, 1992b, p. 180). Because mastery of the skills taught in the class required practice, it was unreasonable to expect participants to discuss this in their journals. Therefore, an analysis of events was excluded from the study. In addition, relational analysis was part of the text analysis, but after five entries, the researchers realized that almost all processes written in the journals were action processes. Therefore, the analysis of relational processes was not carried out. 
In the end, register refers to the degree of formality used in the journal. Formality is expected of a foreign language student addressing a superior and contributes to the learning process (Krashen \& Seliger, 1976).

Members of group A, who were participating in a teacher training course, were asked to write a journal entry from the $2^{\text {nd }}$ to the $11^{\text {th }}$ session. Group B, comprised of English literature university students, met once a week and they submitted their journal entries every week for 10 weeks, starting with the $2^{\text {nd }}$ week.

For group A, the experiment lasted two weeks, and one of the researchers met with the participants five days per week. For group B, journal writing took 10 weeks because the other researcher and the participants only met once per week. All participants submitted their journals when they met with the researchers. The journals were evaluated using the critical discourse feedback form and then returned to the participants the next time they met.

A color coding system was used to show the participants how well they were performing on their journals. Green was used to show satisfaction or improvement in a subcategory. In other words, the color green indicated that the participant was vigilant in a particular subcategory. Black was used to show no change, and red indicated dissatisfaction or retrogression. Figure 9 shows three extracts from a participant's critical feedback form from sessions four, five, and eight.

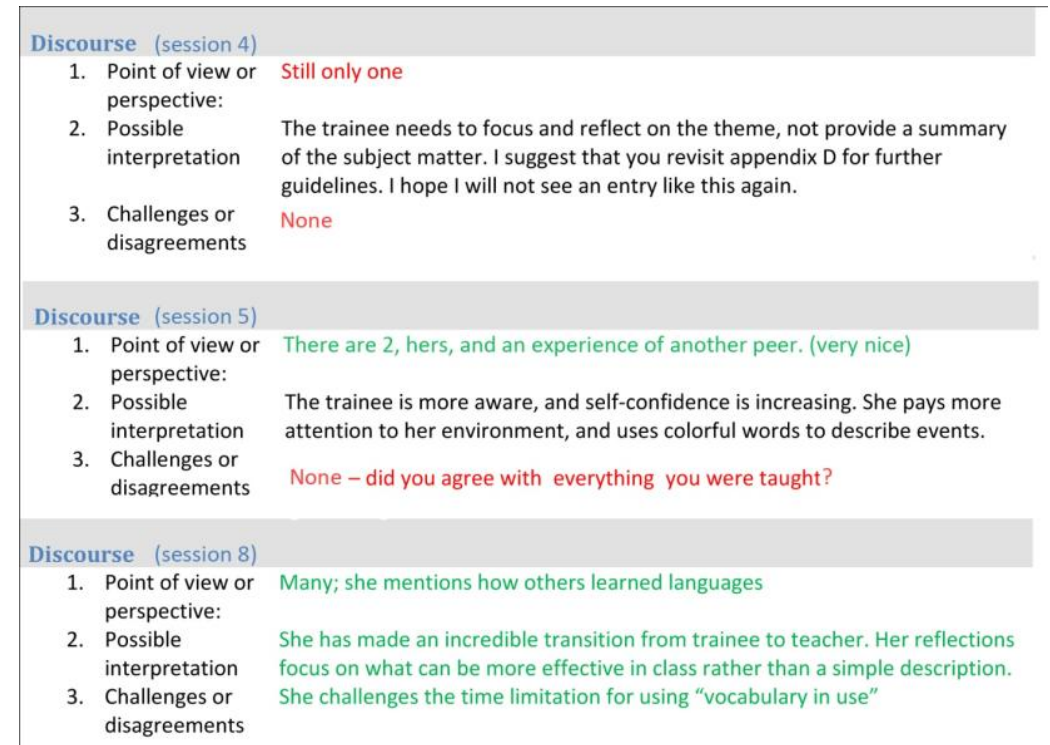

Figure 1. Extracts from critical assessment feedback forms, from one participant, in sessions four, five and eight.

The participants were asked to review their feedback forms and try to be more attentive in the subcategories where they received remarks in red, to make improvements in the subcategories where the remarks were in black, and to continue with the manner in which they were writing in the subcategories where the remarks were in green. Throughout the course of the experiment, the participants were constantly reminded that the feedback form was "a tool and not a rule." This mentality is important because the researchers wanted to avoid biased interpretations of the events that occurred in the classroom.

After 10 sessions, a rater quantified the feedback forms using the critical discourse assessment questionnaire. A second rater quantified 40 journals. The inter-rater reliability was established at 0.7467 .

The same scoring method was used for both group A and group B. The critical discourse assessment questionnaire was used to quantify data from the feedback forms. The questionnaire had three categories, which were genre, discourse, and style. Every subcategory in the critical discourse feedback form was also included in the critical discourse assessment questionnaire, with the exception of two subcategories. The first omitted subcategory of genre was theme because it was a constant in each class session among all the participants. The second exclusion was register in the style category. Register was removed from scoring for two reasons. First, Moon (1999) asserts that reflective journals can be written both in formal and informal registers. Second, almost all entries have a mixed register, which made scoring difficult.

The critical discourse assessment questionnaire was composed of 16 questions. There were five questions for the genre category, three for discourse, and eight for style. With the exception of the subcategories of theme and register, all other questions correspond to the subcategories on the critical awareness feedback form. The questionnaire was comprised of yes/no questions or multiple choice questions depending on the characteristics of the subcategory.

In a review of the literature, there was no mention anywhere that one element (genre, discourse, style) was more important than another element, so it was assumed that they all have equal value. Thus, all three sections were valued at 20 points each, distributed among the subcategories. Because there were a different number of questions in each section, the values of the questions were not equal. The maximum score on the questionnaire was 60 points. 


\section{RESULTS}

The data for group A and group B are organized in separate tables. Data from group A is arranged in Table 1. The letters in the first row represent the individual participant (participants were given a code to ensure anonymity). Each participant wrote ten journals. The scores (obtained from the critical discourse assessment questionnaire) are displayed for each participant.

TABLE 1

SCORES AND DATA ANALYSIS FOR GROUP A

\begin{tabular}{|c|c|c|c|c|c|c|c|c|c|c|c|c|c|c|c|c|}
\hline Sessions & A & Q & $\mathrm{DD}$ & $\mathrm{K}$ & $\mathrm{D}$ & $\mathrm{P}$ & $\mathrm{H}$ & $\mathrm{N}$ & $\mathrm{FF}$ & $\mathrm{R}$ & $\mathrm{HH}$ & $\mathrm{O}$ & $\mathrm{J}$ & MM & $X$ & $\mathrm{C}$ \\
\hline 1 & 19 & 23 & 18 & 32 & 29 & 15 & 17 & 23 & 8 & 20 & 31 & 15 & 22 & 9 & 24 & 25 \\
\hline 2 & 17 & 23 & 15 & 30 & 29 & 18 & 23 & 22 & 9 & 28 & 18 & 18 & 19 & 7 & 22 & 15 \\
\hline 3 & 31 & 35 & 10 & 36 & 28 & 21 & 20 & 28 & 19 & 30 & 37 & 20 & 23 & 15 & 20 & 14 \\
\hline 4 & 23 & 34 & 28 & 35 & 34 & 13 & 21 & 35 & 28 & 30 & 33 & 25 & 28 & 24 & 33 & 39 \\
\hline 5 & 30 & 30 & 18 & 33 & 30 & 11 & 21 & 43 & 37 & 34 & 30 & 18 & 21 & 23 & 34 & 37 \\
\hline 6 & 48 & 32 & 20 & 35 & 38 & 23 & 35 & 39 & 31 & 26 & 29 & 20 & 42 & 24 & 36 & 29 \\
\hline 7 & 37 & 43 & 40 & 52 & 41 & 34 & 36 & 40 & 39 & 46 & 29 & 21 & 39 & 27 & 36 & 43 \\
\hline 8 & 38 & 40 & 39 & 53 & 47 & 22 & 33 & 44 & 35 & 48 & 40 & 25 & 33 & 29 & 34 & 37 \\
\hline 9 & 35 & 42 & 22 & 53 & 42 & 29 & 35 & 44 & 39 & 44 & 29 & 27 & 39 & 33 & 47 & 45 \\
\hline 10 & 47 & 34 & 28 & 56 & 53 & 35 & 34 & 30 & 42 & 54 & 44 & 29 & 40 & 37 & 39 & 45 \\
\hline Corr & 0.81 & 0.75 & 0.60 & 0.90 & 0.92 & 0.74 & 0.86 & 0.66 & 0.91 & 0.60 & 0.40 & 0.83 & 0.83 & 0.96 & 0.86 & 0.80 \\
\hline $\mathrm{b}$ & 2.87 & 1.73 & 1.95 & 3.12 & 2.61 & 2.04 & 2.19 & 1.87 & 3.78 & 2.22 & 0.95 & 1.24 & 2.46 & 3.12 & 2.37 & 3.08 \\
\hline
\end{tabular}

To show how the scores changed over a period of ten sessions, linear regression was used and the slope of the best fitting line was calculated. The scores obtained represent the variables being predicted $(Y)$; the order of session variable $(X)$ is used to make the prediction. Although the order of the sessions is in the ordinal scale, it can be treated as an interval scale, "if the successive categories of the ordinal scale are evenly scaled" (Long \& Freese, 2006, p. 421), which was the case here. To calculate the slope of the best fitting line, first the Pearson Product-moment correlation coefficient between $X$ and $Y$ was calculated (represented by Corr in the Table 1). Then the slopes were calculated, which are represented by $b$ in the Table 1 . As can be seen, all slopes are positive with a mean of 2.35 and a range of 2.83 .

TABLE 2

SCORES AND DATA ANALYSIS FOR GROUP B

\begin{tabular}{|c|c|c|c|c|c|c|c|c|c|c|}
\hline Sessions & 21 & 10 & 5 & 15 & 14 & 12 & 4 & 6 & 19 & 23 \\
\hline 1 & 13 & 10 & 10 & 32 & 30 & 12 & 12 & 18 & 15 & 15 \\
\hline 2 & 15 & 21 & 14 & 29 & 28 & 14 & 28 & 13 & 18 & 22 \\
\hline 3 & 19 & 28 & 20 & 37 & 27 & 21 & 33 & 9 & 21 & 24 \\
\hline 4 & 19 & 12 & 24 & 36 & 25 & 28 & 30 & 29 & 25 & 22 \\
\hline 5 & 21 & 11 & 29 & 40 & 20 & 24 & 34 & 19 & 27 & 23 \\
\hline 6 & 16 & 21 & 15 & 29 & 20 & 21 & 29 & 19 & 19 & 36 \\
\hline 7 & 22 & 27 & 32 & 40 & 18 & 26 & 34 & 30 & 22 & 37 \\
\hline 8 & 23 & 25 & 31 & 41 & 8 & 29 & 30 & 39 & 23 & 30 \\
\hline 9 & 23 & 27 & 33 & 42 & 15 & 30 & 34 & 23 & 26 & 33 \\
\hline 10 & 24 & 28 & 30 & 37 & 20 & 28 & 32 & 28 & 29 & 34 \\
\hline Corr & 0.87 & 0.61 & 0.82 & 0.60 & -0.82 & 0.84 & 0.60 & 0.64 & 0.73 & 0.84 \\
\hline b & 1.08 & 1.48 & 2.29 & 0.95 & -1.80 & 1.74 & 1.30 & 1.90 & 1.06 & 2.04 \\
\hline
\end{tabular}

The data for group B is arranged in Table 2. The numbers in the first row represent the participant. Each participant wrote 10 journal entries, all of which were scored using the critical discourse assessment questionnaire.

As with the previous group, regression analysis was used to identify how the scores changed during the ten sessions. Accordingly, Pearson Product-moment correlation coefficients and the slopes were calculated and are represented by 
Corr and b, respectively. In contrast to what is observed in Table 1 , in Table 2 there is a negative slope of -1.80 . However, all other slopes in Table 2 are positive.

\section{DISCUSSION}

The results obtained from both groups indicate that the feedback scores for most participants increased. The data clearly shows that the scores obtained from session 1 gradually increased until session 10, although the scores of both groups showed fluctuations (see Figure 2 and Figure 3).

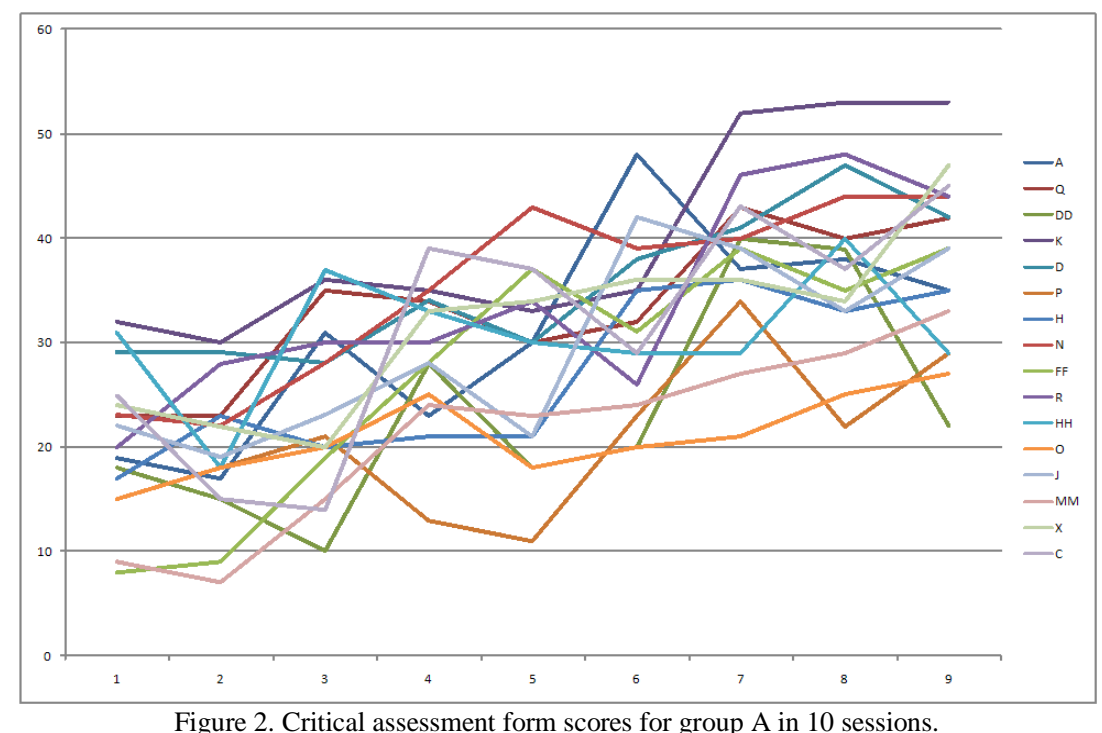

Figure 2. Critical assessment form scores for group A in 10 sessions.

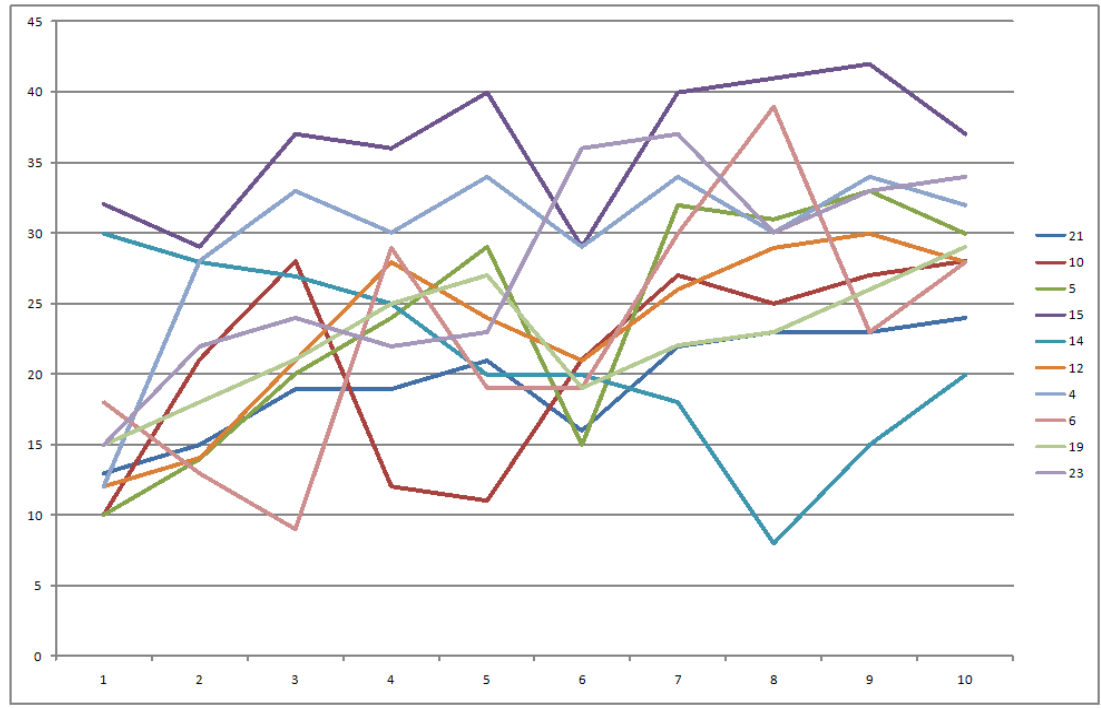

Figure 3. Critical assessment form scores for group B in 10 sessions.

The fluctuations may have been caused by participants' individual differences, such as personality, age, gender, and social status. External factors, such as the theme of the class, environmental conditions, and the instructor, also could have affected the scores.

There are many instances that show how the critical language awareness level increased in 10 sessions for both groups. Almost all participants observed paragraph formation, and used a variety of cohesive devices, which were absent in their earlier journal entries. In session three there were only 4 participants who indicated the use of literary devices. In session 8, 19 participants recognized literary devices, such as "my friend told me that the instructor was new, and he was only trying to win the hearts of the trainees" and "when I asked her how she felt after such a good performance she said 'I am on cloud nine.' I wish I could do a performance like hers." Tense variation also increased in the last three or four journal entries of the majority of the participants. For example while in session three only 8 participants used first, second and third person in their journals, 21 participants used all three forms in session 10. The researchers also observed that participants used affinity such as "may I be allowed to make some suggestions?" or "I'm not sure if my opinion counts but," which were not observed in earlier journal entries. Participants expressed transitivity such as "I need to improve my general English skills" or "at the end I decided that the instructor's idea may be better 
than mine" more frequently in the final 3 sessions. In sum, by using the elements of the order of discourse, the participants had become more critical and more vigilant of their social environment.

Critical discourse analysis has been used as the basis for teaching critical language awareness to students in Australia and the UK (Fairclough, 1992a) in an L1 learning context. In the curricula involving CDA, students are taught how to critically analyze the texts of the culture around them to improve their understanding of their social environment. In a foreign language context similar curricula can be used to raise critical language awareness by teaching learner to analyze their social environment with the elements of the order of discourse.

Unfortunately, there is no published research concerning critical language awareness and EFL writing with an ecological perspective. Studies by Cots (2006) and van Dijk (2001) have provided suggestions on how to increase critical awareness levels in skills such as reading. However, the findings of this research cannot be compared to other studies, unfortunately.

In conclusion, the findings of this study showed that writing could be used to increase critical language awareness in EFL students. Increasing language awareness levels can be accomplished by repetitively exposing students to critical discourse analysis. In this study, the participants were exposed to the elements of the order of discourse because, according to Fairclough (2004), these elements can be used as a method of critical discourse analysis to analyze written and spoken texts. Repeated exposure to the elements allowed students to use them to analyze the spoken and written texts in their environments. As a result, their critical language awareness in a social environment increased.

\section{APPENDIX A CRITICAL AwARENESS FEEDBACK FORM}

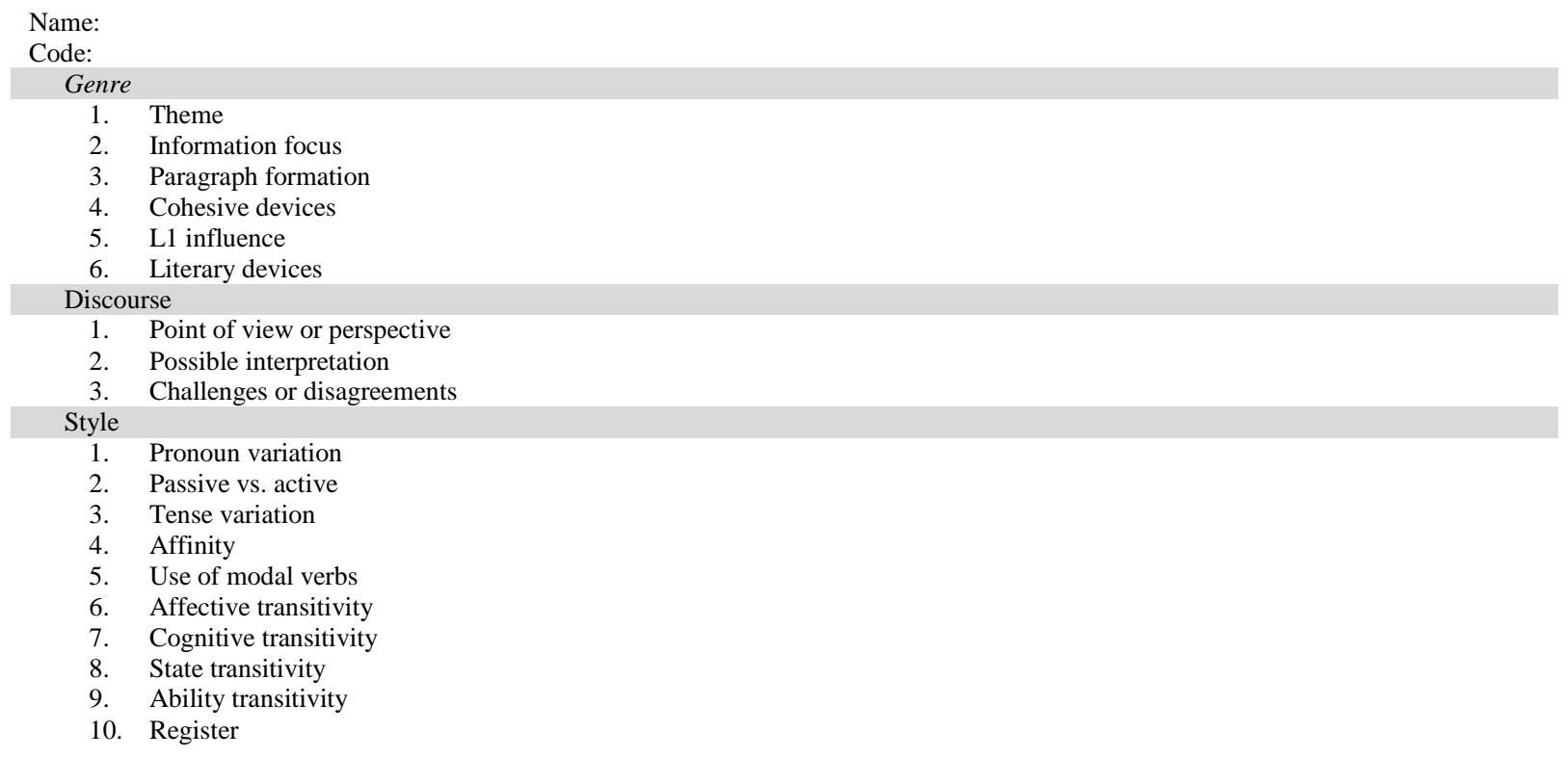

APPENDIX B CRITICAL DisCOURSE ASSESSMENT QUESTIONNAIRE

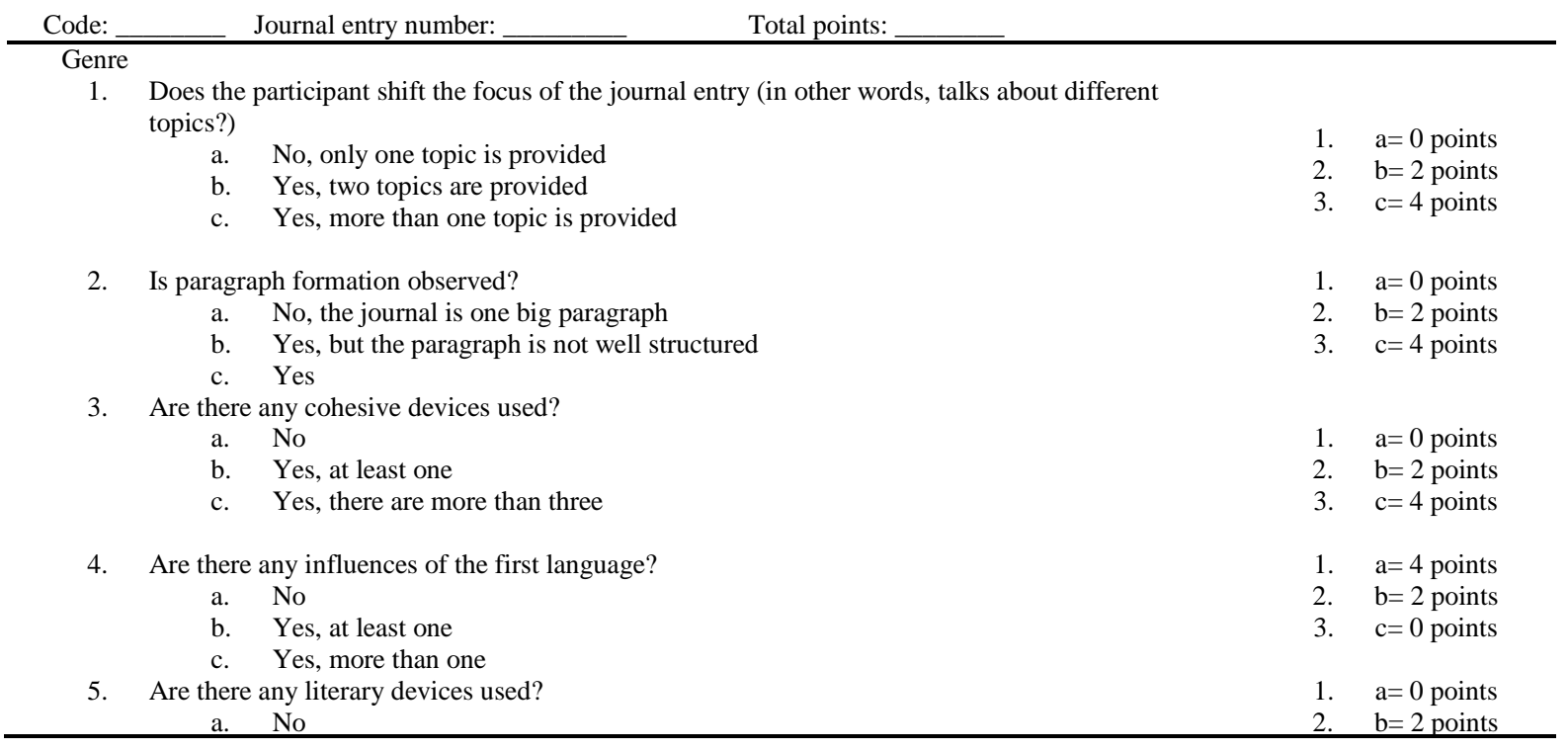




\begin{tabular}{llll}
\hline b. & Yes, at least one & & c=4 points \\
c. & Yes, more than one & Total Genre points $=$ & \\
\hline
\end{tabular}

Discourse

1. Are the points of view of other people expressed in the journal?
a. No
b. Yes, one other point of view is expressed
c. Yes, multiple points of view are expressed
1. $\mathrm{a}=0$ points
2. $\mathrm{b}=4$ points
3. $\mathrm{c}=8$ points

2. Does the journal provide the rater with an insight into the feeling and emotions of the writer?
a. No
b. Yes
1. $\mathrm{a}=0$ points
2. $\mathrm{b}=4$ points

3. Are there any challenges or disagreements mentioned in the journal?
a. No
b. Yes, at least one
c. Yes, there are multiple points mentioned

1. $\mathrm{a}=0$ points

2. $\mathrm{b}=4$ points

3. $\mathrm{c}=8$ points

Total Discourse points=

\begin{tabular}{|c|c|c|}
\hline \multicolumn{3}{|l|}{ Style } \\
\hline 1. & Are there various pronouns used? & \\
\hline & a. No, only first person is used & $\mathrm{a}=0$ points \\
\hline & b. Yes, first person and second person are used & $\mathrm{b}=1$ points \\
\hline & c. Yes, first, second, and third persons are used & $\mathrm{c}=2$ points \\
\hline
\end{tabular}

2. Are there any passive verbs?
a. No
b. Yes, at least one
c. Yes, multiple instances are observed
1. $\mathrm{a}=0$ point
2. $b=1$ points
3. $\mathrm{c}=2$ points

3. Are there any tense (present, past, future, present perfect, past perfect) variation?
a. No, only one tense is used
b. Yes, two tenses are used
c. Yes, more than two tenses are used
1. $\mathrm{a}=0$ point
2. $b=1$ points
3. $\quad \mathrm{c}=2$ points

4. Did the author use affinity at any point?
a. No
1. $\mathrm{a}=0$ points
b. Yes
2. $\mathrm{b}=3$ points

5. Are there any modal verbs used?
a. No
b. Yes, at least one type
c. Yes, multiple types are used

1. $\mathrm{a}=0$ points

2. $\mathrm{b}=1$ points

3. $\mathrm{c}=2$ points

6. Did the author use affective transitivity?
a. No
1. $\mathrm{a}=0$ points
b. Yes
2. $b=3$ points

7. Did the author use cognitive transitivity?
a. No
b. Yes
1. $\mathrm{a}=0$ point
2. $\mathrm{b}=3$ points
a. No
1. $\mathrm{a}=0$ points
b. Yes

8. Did the author use ability transitivity?

Total style points $=$

\section{APPENDIX C GUIDELINES QUESTIONS FOR WRITING A JOURNAL}

\section{A. Content of Learning Journal}

A learning journal should focus on your own personal responses, reactions, and reflections to new ideas or new ways of thinking about a subject that has been introduced to you. It may include:

Significant experiences that have happened during the training session

Research and reading including any visual research, e.g., television, film, etc.

Conversations and discussions with other students or tutors

B. What Should you Write about? 
The most important thing is to make time for your writing--regularly set aside some time to think and then write down your thoughts. Try to focus on using the journal to help you to communicate:

What you think about issues raised on this particular component for the training course

Any inspiration you have had

Your understanding up to this point in time

What you find puzzling, difficult, or contradictory

What you can do understand points that are puzzling, difficult, or contradictory

What you need to know more about, and how can you go about finding out more

How you feel about the way you have approached the issue/topic so far

What new skills or understanding you have gained during the process of writing your learning journal

Finally, writing a learning journal gives you the opportunity to consider the following issues regarding your longterm development:

Have you changed your opinions or values during the process/experience?

How can you improve your learning, thinking, and working in the future?

Have you identified the next step(s) for your further development?

\section{REFERENCES}

[1] Allen, D. (2004). Oxford Placement Test. Oxford: Oxford University Press.

[2] Bolinger, D. (1990). Language: The loaded weapon. London: Longman.

[3] Bourdieu, P. (1991). Language and symbolic power. Cambridge, MA: Harvard University Press.

[4] Chouliaraki, L., \& Fairclough, N. (1999). Discourse in late modernity. Edinburgh: Edinburgh University Press.

[5] Cots, J. M. (2006). Teaching 'with an attitude': Critical discourse analysis in EFL teaching. ELT Journal, 60.4, 336-345.

[6] Fairclough, N. (1992a). Critical language awareness. Harlow: Longman.

[7] Fairclough, N. (1992b). Discourse and social change. Cambridge: Polity Press.

[8] Fairclough, N. (1995). Language and power. London: Longman.

[9] Fairclough, N. (2003). Analysing discourse: Textual analysis for social research. London: Routedge.

[10] Fairclough, N. (2004). Semiotic aspects of social transformation and learning. In R. Rogers (ed.), An introduction to critical discourse analysis in education. Mahwah, NJ: Lawrence Erlbaum Associates, 225-235.

[11] Krashen, S. D., \& Seliger, H. W. (1976). The role of formal and informal environments in second language learning: A pilot study. Linguistics, 172, 15-21.

[12] Lewis, C., \& Ketter, J. (2004). Learning as social interaction: Interdiscursivity in a teacher and researcher study group. In R. Rogers (ed.), An introduction to critical discourse analysis in education. Mahwah, NJ: Lawrence Erlbaum Associates, 117-145.

[13] Long, J., \& Freese, J. (2006). Regression models for categorical dependent variables using stata (2nd edn.). College Station, TX StataCorp LP.

[14] Moon, J. (1999). Learning journals: A handbook for academics, students and professional development. London: Kogan Page.

[15] Rogers, R. (2004). Setting an agenda for critical discourse analysis in education. In R. Rogers (ed.), An introduction to critical discourse analysis in education. Mahwah, NJ: Lawrence Erlbaum Associates, 237-254.

[16] Sarroub, L. K. (2004). Reframing for decisions: Transforming talk about literacy and assessment among teachers and researchers. In R. Rogers (ed.), An introduction to critical discourse analysis in education. Mahwah, NJ: Lawrence Erlbaum Associates, 97-116.

[17] Sinclair, B., McGrath, I., \& Lamb, T. (2000). Learner autonomy, teacher autonomy: Future directions. London: Longman.

[18] Sparks-Langer, G., \& Colto, A. (1991). Synthesis of research on teachers. Educational Leadership, 48.6, 37-44.

[19] Sparks-Langer, G., Simmons, J., Pasch, M., Colton, A., \& Starko, A. (1990). Reflective pedagogical thinking: How can we promote it and measure it? Journal of Teacher Education, 41.5, 23-32.

[20] van Dijk, T. (2001). Multidisciplinary CDA: A plea for diversity. In R. Wodak \& M. Meyer (eds.), Methods of critical discourse analysis. London: Sage, 95-120.

[21] van Lier, L. (1998). The relationship between consciousness, interaction and language learning. Language Awareness, 7.2, $128-145$.

[22] van Lier, L. (2004). The ecology and semiotics of language learning: A sociocultural perspective. Norwell, MA: Kluwer Academic Publishers.

[23] Wenden, A. (1986). What do second-language learners know about their language learning? A second look at retrospective accounts. Applied Linguistics, 7.2, 186-205.

[24] Woodside-Jiron, H. (2004). Language, power, and participation: Using critical discourse analysis to make sense of public policy. In R. Rogers (ed.), An introduction to critical discourse analysis in education. Mahwah, NJ: Lawrence Erlbaum Associates, 173-206.

Parviz Maftoon is an associate professor in the School of Foreign Languages and Literature at the IAU Science and Research Brach, where he teaches TEFL courses. He has carried out most of his research in the field of applied linguistics, focusing on EFL writing, foreign language teaching and learning, and ESP.

Soroush Sabbaghan is a lecturer and PhD candidate in the School of Foreign Languages and Literature at the IAU Science and Research Brach, where he teaches English. His research interests are foreign language teaching and learning from an ecological perspective, language awareness, and the writing process. 